2017 AATS Innovation Summit

Saturday, April 29, 2017

Boston Marriott Copley Place Hotel

Boston, Massachusetts, USA

Course Director

W. Randolph Chitwood

\section{Program Overview}

Ignite your spirit for innovation at the 2017 AATS Innovation Summit. The one-day program will assist cardiothoracic surgeons in developing new clinically applicable technology by obtaining cross-specialty knowledge needed for novel idea generation, protecting intellectual property, prototyping, developmental funding, clinical trials, regulatory pathways, and industry relations.

\section{The Western Thoracic Surgical Association}

\section{WTSA 43rd Annual Meeting}

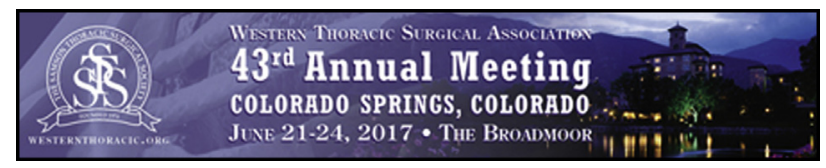

Save the date! The WTSA's 43rd Annual Meeting will be held at the Broadmoor in Colorado Springs, Colorado, from June 21 to 24, 2017.

\section{Applications for Membership}

The WTSA is now accepting Applications for Membership online for Active as well as Candidate membership status. Visit the WTSA Web site at www.westernthoracic.org to read the complete membership eligibility requirements and to initiate an online application.

\section{Active Member}

$\$ 375.00$ annually, plus $\$ 50.00$ initiation fee

Applicant must meet all membership criteria, including but not limited to:

- Reside within or have completed a cardiothoracic residency training program within the geographic limits of the Association.

- Have been engaged in the practice of thoracic and cardiovascular surgery for at least three years following completion of postgraduate training. If a candidate completed his/her thoracic surgical residency or a oneyear clinical fellowship in an institution within the geographic limits of the Association, such completion may count toward one of the three years of practice.
- Have a full and unrestricted license to practice medicine in his or her respective state or province, and have a current appointment on the surgical staff of a hospital with no reportable action pending which could adversely affect such applicant's staff privileges at any hospital.

\section{Candidate Member}

$\$ 100.00$ annually

Applicant must meet all membership criteria, including but not limited to:

- Be matched or enrolled in either a cardiothoracic surgery education program accredited by the Residency Review Committee for Thoracic Surgery under the authority of the ACGME or a program approved for cardiothoracic surgery education by the Royal College of Surgeons of Canada - or their equivalency-from within the Association's geographic limits. Individuals who have completed their education in one of the above programs but do not yet meet all of the criteria for Active membership also are eligible to apply for Candidate membership. Individuals who trained outside the Association's geographic limits who are now residing within the Association's boundaries but do not yet have three years in practice may also apply for Candidate membership.

An application must include the following uploads: a photo, a complete curriculum vitae with bibliography, and, for Active applicants, the 3 most significant articles that $\mathrm{s} / \mathrm{he}$ personally wrote. The application must be completed and submitted online by March 1, 2017, and all support letter(s) (three for Active applicants, one for Candidates) uploaded by that applicant's sponsor(s) by March 31, 2017, in order for the applicant to be considered for election to membership at the 2017 Annual Meeting. 